American Journal of Environmental Sciences 8 (2): 158-161, 2012

ISSN 1553-345X

(C) 2012 Science Publications

\title{
The Effect of Water on The Strength of Building Stones
}

\author{
Bellopede Rossana and Marini Paola \\ Department of Environment, Land and Infrastructures Engineering, Faculty of Engineering, \\ Politecnico di Torino, Corso Duca degli Abruzzi 24-10129 Torino, Italy
}

\begin{abstract}
Problem statement: Water is one of the main causes of stone decay and the presence of water alone inside a stone could cause a decrease in its mechanical strength. In order to study the effect of water on the mechanical strength of stones, three Italian stones, which have historically been used for balconies, have been studied: Pietra di Luserna, Pietra Verde Argento and Pietra di Courtil. Approach: A comparison had been made between the effect of artificial ageing, by means of freeze and thaw cycles (where the increase in pores produced by iced water mechanically weakens the stone) and the effect of saturation on sound specimens subjected to flexural strength tests. Results: The results had shown that the three stones were very resistant to freeze and thaw cycles, but their mechanical strength decreases in wet condition. Conclusion/Recommendations: On the basis of the obtained results, it can be stated that mechanical strength values in wet conditions can be considered, in the planning of structural stonework for exterior use. As demonstration the case of a Pietra di Luserna balcony, where fault is occurred, a is reported.
\end{abstract}

Key words: Influence of water, mechanical resistance, saturation

\section{INTRODUCTION}

It is known, in the scientific stone community, that water has a negative influence on materials in use (Fort, 2006; Chen et al., 2004; Winkler, 1994; Hudec, 1998): its effects can be seen not only on durability but also on the safe dimensioning of structures. In the last few years, there have been many cases of faults in stone modillions or stone balcony slabs (Fig. 1-3). These faults have mainly occurred in historical buildings and the involved stones have been used for centuries, normally with very good performances and resistance to decay. A database has been set up pertaining to 62 cases of stone balconies faults in Piedmont (Perino, 2008). This database reports the kind of stone and its conditions, the dimensional characteristics and the structure of the balcony.

Almost all the standardized ageing methods used to simulate weathering on natural stones involve water, which, together with other factors, indirectly induces weathering: thermal shock (EN 14066: specimens cooling in water), freeze and thaw (EN 12371: iced water in stone pores), salt crystallization (EN12370: water carrying salt into the pores), resistance to thermal and moisture cycling (prEN 16306: the bottom of the specimen is set on a wet surface). However, the loss in mechanical strength for all these standardised ageing methodologies is evaluated using dried specimens subjected to the weathering cycles and comparing them with dried specimen in natural conditions.

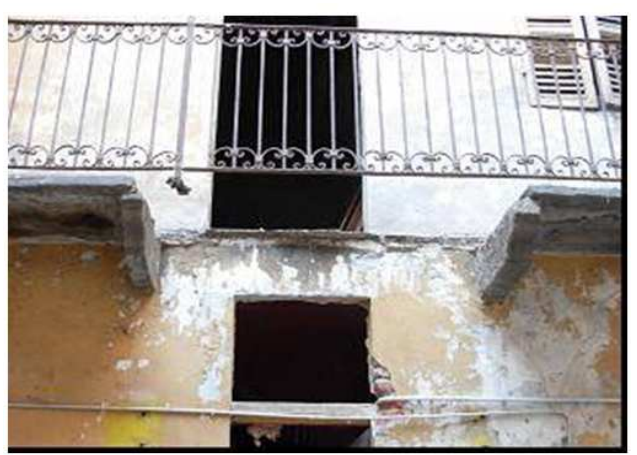

Fig. 1: The remains of a balcony in Pietra di Courtil

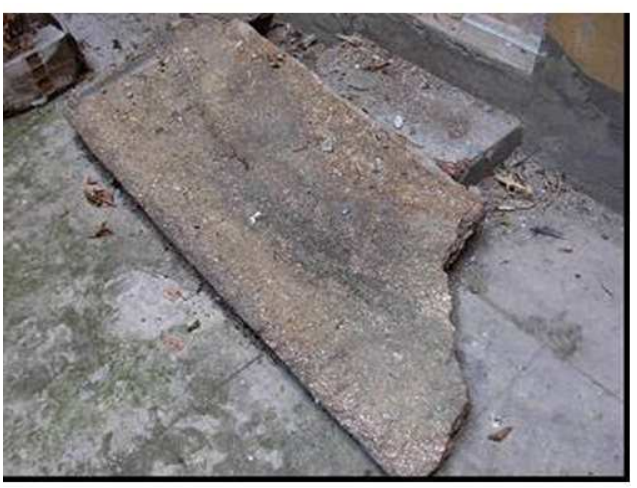

Fig. 2: The broken balcony slab of Fig. 1

Corresponding Author: Bellopede Rossana, Department of Environment, Land and Infrastructures Engineering, Politecnico di Torino, Corso Duca degli Abruzzi 24-10129 Torino, Italy 
Am. J. Environ. Sci., 8 (2): 158-161, 2012

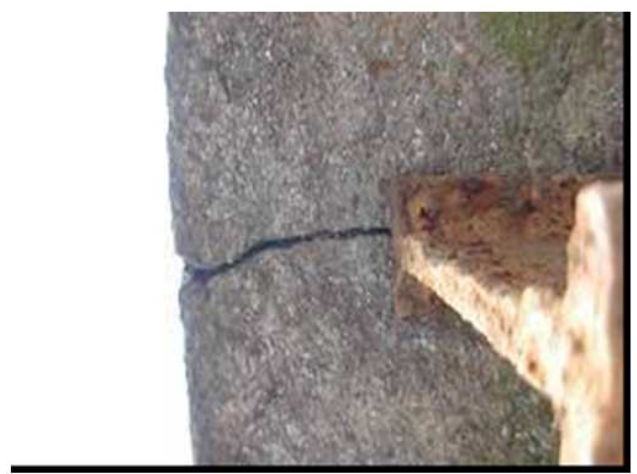

Fig. 3: Details of a Verde Argento balcony were the beam leans in correspondence to a fracture

However, the presence of water in the pores of a stone is the direct cause of loss in mechanical resistance. In a recent paper, Torok and Vásárhelyi (2010) has asserted that rocks with high porosity (such as travertine) behave in a completely different way under dry and water saturated conditions (reduction in strength with an increase in the water content). In this research the dependence of mechanical behaviour on the water content has been pointed out even for the stones with low porosity. The water in the pore softens the bonding strength (especially in the presence of phyllosilicates like micas, which are present in the three stones studied in this study).

The water adsorbed in small pores can be considered like osmotic fluids which cause expansive and, ultimately, destructive forces in the rock (Michalopoulos and Triafilidis, 1976; Hudec, 1998).

Winkler (1994), on the basis of previous work (Colback and Wiid, 1965), proposed a correlation between compressive strength in wet and dry conditions. This method has been used by some authors (e.g., Wasserman, 2002) to assess the quality of stones. Some catalogues or publications have presented the mechanical properties of stones in wet and dry conditions (Smith, 1999), but European Standards only foresee tests in dry conditions (with the exception of the rupture strength for armourstones in wet conditions: EN 1926 Annex A), while (ASTM C880 2009) foresees tests in wet conditions to determine the flexural strength of stone, if necessary.

\section{MATERIALS AND METHODS}

This study has been organized in two directions: the evaluation of the indirect action of water on the weathering of rocks and the study of the effect of the presence of water as the direct cause of stone weakness.

The indirect action of water on the weathering of rocks has been evaluated at different ageing steps, induced from freeze-thaw cycles by means of destructive and non destructive tests.

To evaluate the direct influence of the water on the stone, flexural strength tests were conducted on specimens in dry and wet conditions.

\section{The analyzed stones are:}

Pietra di Luserna: This gneiss outcrops over an area of about $50 \mathrm{~km}^{2}$ between Val Pellice and the Po Valley (Piedmont, Italy). Some of its characteristics, such as its easy splitting and the high resistance and durability, have favoured its utilization for both indoor (floorings, windowsills) and outdooor (balconies, modillions, staircases, coverings, fireplaces and coverages) uses over the centuries. In the 19th century, the greatest architectural work in Italy was the Mole Antonelliana in Turin, where Luserna stone was employed by Alessandro Antonelli (1798-1888) to cover the great dome and the steeple above.

Pietra di Courtil: This micascist comes from the Hône quarry (Aosta Valley, Italy). The stone has probably been used since the Middle Ages, but its systematic exploitation started at the beginning of 19th century. It has been used both indoors and outdoors (mainly to cover roofs) because of its rustic aspect and its hardness properties.

Pietra Verde Argento: This gneiss is exploited in the Settimo Vittone quarries (Piedmont, Italy). This green coloured stone, characterized by the presence of silver mica, has been used both indoors and outdoors for centuries.

In order to reproduce the effect of iced water on stone specimens, the stones have been subjected to artificial ageing by means of freezing-thawing cycles according to the ECS (2001) standard. A total of 60 cycles were performed. The same specimens were tested at $\mathrm{t}_{0}$, at intermediate steps and at $\mathrm{t}_{60}$ (after 60 cycles) by means of non destructive tests (open porosity according to BSIS (2007) and Ultrasonic Pulse Velocity according to BSIS (2005). The flexural strength test was performed, according to BSIS (2007) on four different sets of specimens, two (dry and wet) in natural conditions and the other two (dry and wet) subjected to 60 freezing and thawing cycles.

The dry condition was obtained by drying the specimens at a temperature of $(70 \pm 5){ }^{\circ} \mathrm{C}$ to constant mass. The saturated condition was reached following EN 13755 methodology, clause 7, until a constant mass is reached. The constant mass was assumed to have been attained when the difference between two weighings, at an interval of $(24 \pm 2) \mathrm{h}$, is no greater than $0.1 \%$ of the first of these two masses. 
Am. J. Environ. Sci., 8 (2): 158-161, 2012

\section{RESULTS AND DISCUSSION}

Tests on weathered samples: The freezing and thawing cycles did not produce an appreciable decay in the three stones.

The results of the open porosity test are shown in Table 1 as the mean value of 6 specimens. The variation in $p_{o}$ from $t_{0}$ to $t_{60}$ is very limited. The results are reported with a precision of $0.01 \%$ and a very slight decay can be appreciated for the Pietra di Courtil, as can be seen from the $6 \%$ increase in $\mathrm{p}_{\mathrm{o}}$.

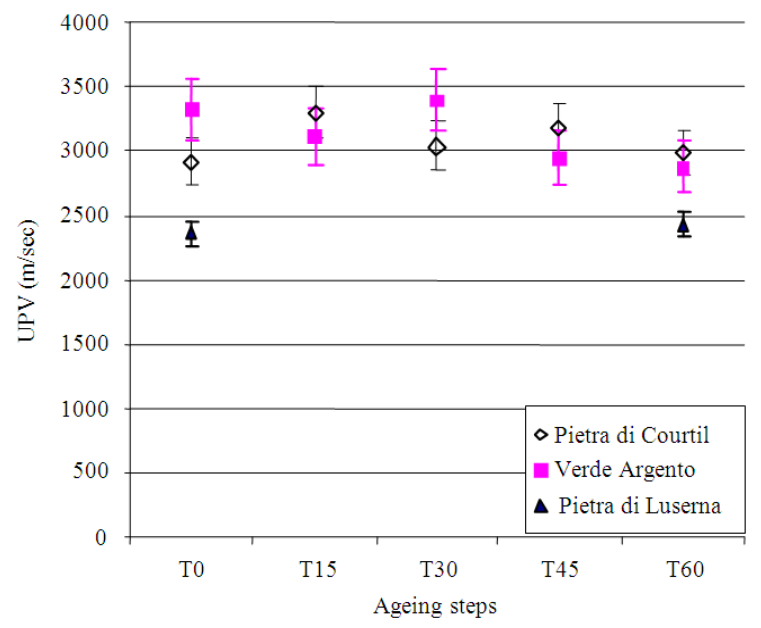

Fig. 4: UPV (indirect method) on Pietra di Courtil, Verde Argento, Pietra di Luserna for each ageing step

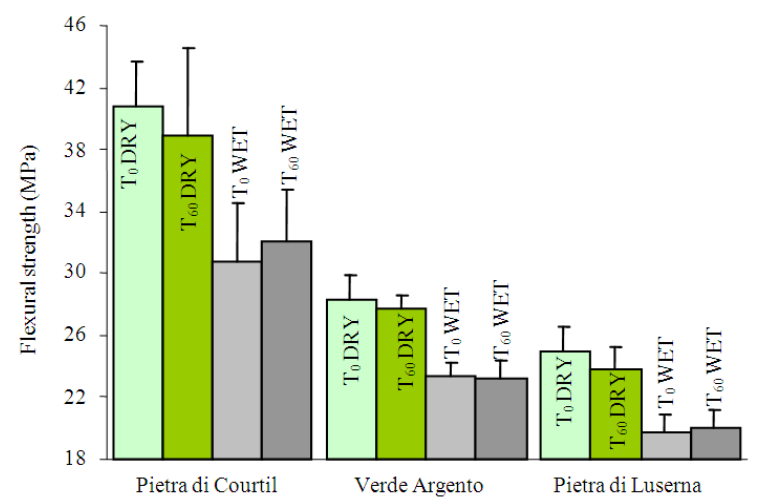

Fig. 5: Flexural strength results in dry and wet conditions at $\mathrm{T} 0$ and $\mathrm{T} 60$ ageing steps

Table 1: Determination of open porosity at different decay steps

\begin{tabular}{llll}
\hline Cycles & $\begin{array}{l}\text { Pietra di } \\
\text { Courtil } \mathrm{p}_{\mathrm{o}}(\%)\end{array}$ & $\begin{array}{l}\text { Pietra Verde } \\
\text { Argento } \mathrm{p}_{\mathrm{o}}(\%)\end{array}$ & $\begin{array}{l}\text { Pietra di } \\
\text { Luserna } \mathrm{p}_{\mathrm{o}}(\%)\end{array}$ \\
\hline $\mathrm{T}_{0}$ & 0,70 & 0,64 & 0,83 \\
$\mathrm{~T}_{30}$ & 0,71 & 0,64 & n.d. \\
$\mathrm{T}_{60}$ & 0,74 & 0,64 & 0,84 \\
\hline
\end{tabular}

Table 2: Flexural strength variations from dry to wet condition at $\mathrm{T}_{0}$ and $\mathrm{T}_{60}$

\begin{tabular}{llll} 
& Flexural strength variation from dry to wet condition (\%) \\
& - & & \\
& Pietra di & Pietra Verde & Pietra di \\
Cycles & Courtil & Argento & Luserna \\
\hline $\mathrm{T}_{0}$ & -24 & -17 & -21 \\
$\mathrm{~T}_{60}$ & -17 & -16 & -15 \\
\hline
\end{tabular}

The results of UPV for each freeze-thaw step are reported in the graph of Fig. 4. The graph shows no substantial variations for any of the three kinds of rock.

As far as the destructive tests are concerned, the flexural resistance test performed on the dry specimens subjected to the ageing cycles was varied from to 2$4.8 \%$ compared with the one executed on dry specimens in a natural state. It should be considered that the comparison is made between two different sets of specimens and the variability of the stone should be taken in account.

Tests on saturated samples: The comparison between the results of flexural strength on specimens in dry conditions compared with wet conditions, shows a decrease in the values from $5-24 \%$. The flexural strength values for the three kinds of stones are reported in Fig. 5 in dry conditions and in wet conditions, at both $\mathrm{t} 0$ and $\mathrm{t} 60$.

The use of mechanical strength in dry condition to measure the admissible strength in the project calculation, does not take into account the direct weakening effect of water on stone.

From the results of flexural strength tests in dry and wet conditions, the three stones, even though very durable, suffered from the effects of water saturation, which considerably lowered their resistance. The flexural strength of all the tested stones was much lower on wet specimens than on dried specimens, in each ageing step (Table 2).

\section{CONCLUSION}

Both the non destructive and destructive test results have shown that the three analysed stones, all of which are silicatic and metamorphic with low porosity (Table 1), do not suffer from the effects of frozen water in the pores, as can be confirmed from an observation of their state of conservation when used in historical buildings.

The flexural strength values obtained from specimens tested in wet conditions are surely a guarantee of higher safety when dimensioning the stonework of buildings. 


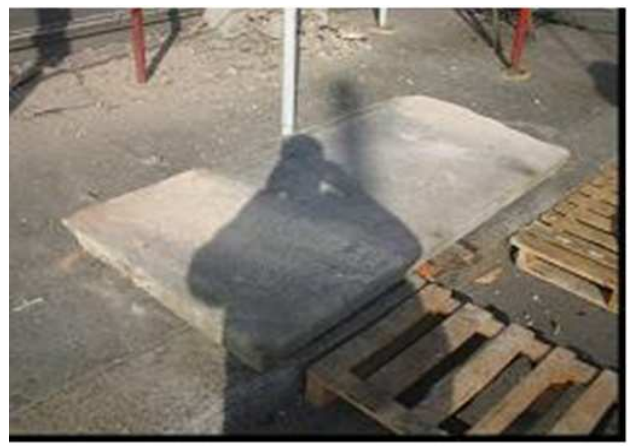

Fig. 6: The Pietra di Luserna broken balcony slab due to wrong project calculation

In case ${ }^{\circ} 15$ of the database (Perino, 2008), a balcony in Pietra di Luserna in which a fault occurred (Fig. 6), the maximum moment MMAX of $1.68 \mathrm{kN} \mathrm{m}^{-1}$ and the section modulus $\mathrm{W}$ of $0.33 \mathrm{~m}^{3}$, computed from balcony measurements (length $200 \mathrm{~cm}$, width $50 \mathrm{~cm}$, thickness 8 $\mathrm{cm}$, modillions distance $174 \mathrm{~cm}$ ), gives $\sigma \max$ (maximum flexural strength) according to Eq. 1:

$\sigma_{\text {max }}=\frac{\mathrm{M}_{\mathrm{MAX}}}{\mathrm{W}}=\frac{1.68}{0.33}=5.0 \mathrm{MPa}$

For the Pietra di Luserna stone:

$$
\begin{aligned}
& \sigma_{\text {dry }}=22.8 \mathrm{MPa} \\
& \sigma_{\text {wet }}=18.0 \mathrm{MPa}
\end{aligned}
$$

Taking into account a safety coefficient of 4 , the admissible strengths $\sigma_{\text {admdry }}$ and the $\sigma_{\text {admwet }}$ are:

$$
\begin{aligned}
\sigma_{\text {admdry }} & =5.7 \mathrm{MPa} \\
\sigma_{\text {admwet }} & =4.5 \mathrm{MPa}
\end{aligned}
$$

$\sigma_{\text {admwet }}$ of $4.5 \mathrm{MPa}$ is lower then the $\sigma_{\max }$ of 5.0 MPa calculated from the balcony dimensions. This could be the reason for the fault, together with general weathering (traffic vibrations, building setting, trampling and load action) over about a hundred years.

\section{REFERENCES}

ASTM C880: 2009. Standard Test method for Flexural Strength of Dimension Stone. ASTM International, West Conshocken.

BSIS, 2005. Natural Stone Test Methods. Determination of Sound Speed Propagation. 1st Edn., BSI Standards, ISBN: 0580452689, pp: 16.

BSIS, 2007. Natural Stone Test Methods. Determination of Flexural Strength Under Concentrated Load. 1st Edn., BSI Standards, ISBN: 0580499200, pp: 18.
BSIS, 2007. Natural Stone Test Methods. Determination of Real Density and Apparent Density, and of Total and Open Porosity. 1st Edn., BSI Standards, ISBN: 0580499197, pp: 14.

Chen, T.C., M.R. Yeung and N. Mori, 2004. Effect of water saturation on deterioration of welded tuff due to freeze-thaw action. Cold Regions Sci. Technol., 38: 127-136. DOI: 10.1016/j.coldregions.2003.10.001

Colback, P.B.S. and B.L. Wiid, 1965. The influence of moisture content on compressive strength of rocks. Proceedings of the 3rd Canadian Symposium On Rock Mechanics, Toronto, Mines Branch, Dept of Mines and Technical Survey, Ottawa, pp: 65-83.

ECS, 2001. Natural Stone Test Methods: Determination of frost Resistance. 1st Edn., CEN, European Committee for Standardization, Brussels pp: 24.

Fort, R., 2006. Heritage, Weathering and Conservation.1st Edn., Taylor and Francis, London, ISBN-10: 0415412722 pp: 1026.

Hudec, P.P., 1998. Rock properties and physical processes of rapid weathering and deterioration. Proceedings of the 8th International IAEG Congress, (IAEGC' 998), Balkema, Rotterdam, pp: 335-341.

Michalopoulos, A.P. and G.E. Triafilidis, 1976. Influence of water on hardness, strength and compressibilità of rocks. Bull. Ass. Eng. Geol. 13: 1-21.

Perino, L., 2008. Balconi in pietra: casi studio e prove di durabilità. Tesi di laurea. Politecnico di Torino.

Smith, M.R., 1999. Stone: Building Stone, Rock Fill and Armourstone in Construction. 1st Edn., Geological Society, London, ISBN-10: 1862390290, pp: 478.

Torok, Á. And B. Vásárhelyi, 2010. The influence of fabric and water content on selected rock mechanical parameters of travertine, examples from hungary. Eng. Geol., 115: 237-245. DOI: 10.1016/j.enggeo.2010.01.005

Wasserman, I., 2002. Assessment of the durability of two natural stones intended for the conservation of the historical masonry sea wall in the old Town of Acre.

Winkler, E.M., 1994. Stone in Architecture: Properties, Durability. 1st Edn., Springer, Berlin, ISBN-10: 3540576266, pp: 313. 